\title{
Anti-Ri-associated paraneoplastic cerebellar and brainstem degenerative syndrome
}

\author{
${ }^{1} \mathrm{JK}$ Tay, ${ }^{2} \mathrm{~J}$ Miller, ${ }^{3} \mathrm{~A}$ Joshi, ${ }^{4} \mathrm{RJ}$ Athey \\ ${ }^{1}$ Core Medical Trainee, Northern Deanery, Newcastle upon Tyne; ${ }^{2}$ Consultant Neurologist, Newcastle upon Tyne Hospitals NHS Trust; \\ ${ }^{3}$ Consultant Neuropathologist, Newcastle upon Tyne Hospitals NHS Trust, Newcastle upon Tyne; ${ }^{4}$ Consultant in Elderly Medicine, Gateshead \\ Health NHS Trust, Gateshead, UK
}

\begin{abstract}
We present the case of a female patient with a subacute paraneoplastic brainstem neurological syndrome associated with breast cancer and the development of anti-Ri antineuronal antibodies (ANNAs). It is an important syndrome to identify because of the need for urgent investigation and management to reduce progressive and irreversible neurological deterioration and to recognise the associated risks of bulbar and central respiratory failure. Diagnosis can be confounded if the anticipated normality of imaging and cerebrospinal fluid (CSF) studies is not appreciated. Positive antineuronal screening can provide rapid support for a paraneoplastic aetiology. Urgent and extensive investigation to identify the underlying tumour is imperative since neurological outcome is dependent on the rapidity of commencement and efficacy of tumour therapy. We discuss the symptoms, pathophysiology, diagnosis, treatment and prognosis of paraneoplastic neurological syndromes.
\end{abstract}

KEYWORDS Breast cancer, paraneoplastic syndrome, antineuronal antibody, anti-Ri

DECLARATION OF INTERESTS No conflicts of interest declared.
Correspondence to RJ Athey, Jubilee Wing, Queen Elizabeth Hospital, Sheriff Hill, Gateshead, Tyne \& Wear NE9 6SX, UK

tel. +44 (0) 19I 4453844 e-mail richardathey@doctors.org.uk

\section{CASE REPORT}

A 67-year-old female presented initially with a six-week history of malaise, fever, nine kilogram $(\mathrm{kg})$ weight loss and two weeks of blurring of vision. In addition there had been a deterioration in memory, confusion and a change in behaviour and personality noticed by her family but not by the patient herself. Initial investigation by her general practitioner had led to a referral to the endocrinology team for further investigation for hyponatraemia. She was found to have syndrome of inappropriate antidiuretic hormone (SIADH) and was awaiting further investigation at the time of her admission.

She was normally well, had no significant past medical history and was not taking regular medications. She was a non-smoker and consumed minimal alcohol. She had travelled to Gambia in October 2009, Nepal in March 2009, and Sri Lanka in December 2008.

On admission, she was febrile with a temperature of $38^{\circ} \mathrm{C}$ and remained intermittently pyrexial throughout her admission. She had partial bilateral horizontal gaze palsy with normal vertical eye movements. Visual acuity and fundal examination were normal. She was unsteady on heel-toe walking with mild left-sided dysmetria. Auscultation of the chest was clear and the abdomen was soft with no organomegaly or masses. There was no palpable lymphadenopathy.
Investigations included serum sodium 126 moles per litre $(\mathrm{mol} / \mathrm{L})$, white cell count $\mid \mathrm{I} .4 \times 10^{9}$ per litre, C-reactive protein $<2$ milligrams per litre $(\mathrm{mg} / \mathrm{L})$, and erythrocyte sedimentation rate of 2 millimetres per hour $(\mathrm{mm} / \mathrm{hr})$. We were concerned about the possibility of an infectious cause for her symptoms due to the fluctuating pyrexia and recent foreign travel and initial investigations concentrated in this area. Blood, urine and stool cultures were negative. Autoantibodies, hepatitis and a virology screen plus extensive tropical and infectious disease serology were all unremarkable. A chest $\mathrm{X}$-ray was normal and no cardiac vegetation was seen on echocardiogram.

Cerebrospinal fluid (CSF) analysis demonstrated a white cell count range of $12-14 \times 10^{6} / \mathrm{L}$, predominantly lymphocytes. Protein in the CSF was mildly raised $(0.44$ $\mathrm{g} / \mathrm{L})$, CSF glucose was 3.9 millimoles per litre (mmol/L) and CSF oligoclonal bands were positive. No organisms were seen on Gram stain or any growth on CSF culture. Analysis of the CSF for acid fast bacilli, herpes simplex viruses, varicella zoster virus DNA, Epstein-Barr virus, cytomegalovirus and cryptococcal antigen were all negative. Cytology of CSF was normal.

Computed tomography (CT) and magnetic resonance imaging (MRI) scans of the brain were normal. An electromyogram (EMG) scan did not show any evidence of neuromuscular junction disorder, myopathy or neuropathy. A CT scan of the thorax and abdomen 


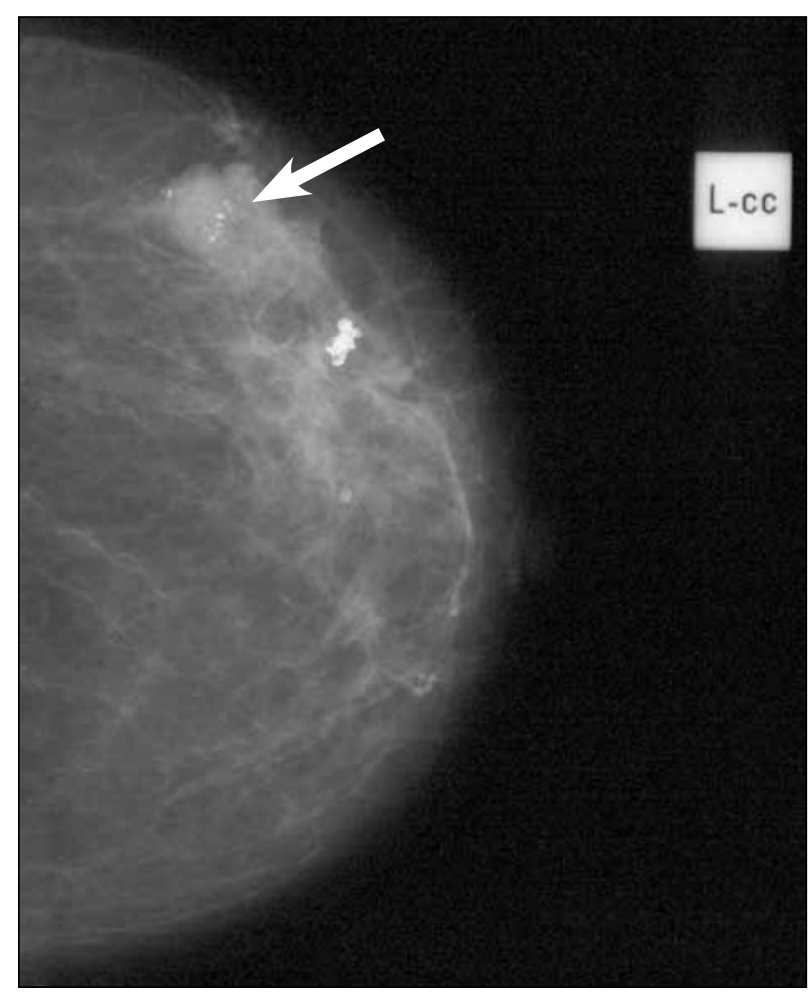

FIGURE I Craniocaudal mammogram of the left breast showing an irregular mass in the outer half containing microcalcification consistent with breast carcinoma (arrow).

revealed a 2 centimetre $(\mathrm{cm})$ diameter soft tissue mass in the left breast but no other significant abnormality. Mammography (Figure I) and ultrasound showed a likely breast carcinoma with three out of nine axillary lymph nodes involved which was subsequently confirmed on core biopsy to be a grade three oestrogen receptor positive but Herceptin receptor negative ductal carcinoma with metastatic lymph node involvement. This had not been palpable clinically. Cancer antigen I5-3 was mildly raised (30.2 thousand units per litre [ku/L]). Other tumour markers including CA-125 and carcinoembryonic antigen (CEA) were normal.

Subsequent investigations demonstrated the presence of a positive antineuronal antibody ANNA-2 or anti-Ri in the serum. Other ANNAs including voltage-gated potassium and calcium channel antibodies, acetylcholine receptor antibodies, anti-Yo, anti-Hu and anti-Ma antibodies were all negative.

Over a four-week period our patient suffered a progressive neurological decline. Partial ptosis and bulbar involvement developed with dysphagia and dysarthria and the gaze palsy deteriorated to a complete horizontal palsy suggesting extension of the initial pontine localisation. She then deteriorated further with type II respiratory failure $(\mathrm{pH} 7.23, \mathrm{PCO} 210.2$, Base excess +4$)$ requiring artificial invasive ventilation. The patient demonstrated reduced respiratory drive,

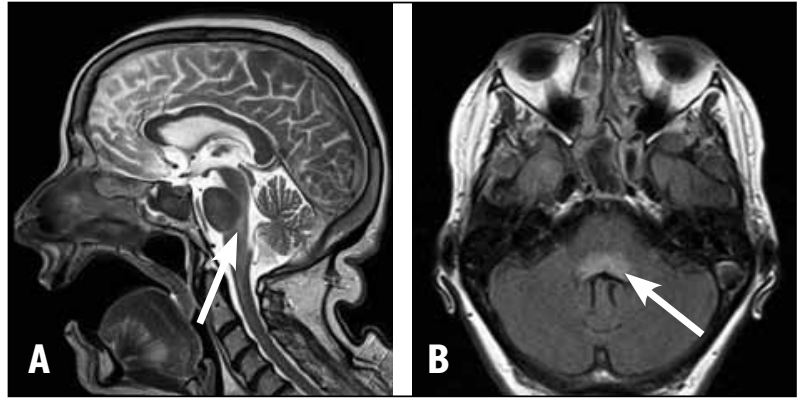

FIGURE 2 Magnetic resonance imaging scans from late in the patient's course showing abnormal high signal in the dorsal pons (arrow). A Sagittal T2 image. B Axial T2 flair image.

becoming apnoeic when asleep but was able to maintain adequate ventilation when awake, indicating involvement of parapontine reticular formation. It is possible that chronic nocturnal hypoventilation was responsible for the mild cognitive change initially perceived by her family.

Our patient was commenced on letrozole $2.5 \mathrm{mg}$ daily and underwent an urgent left-sided mastectomy with axillary node clearance while on invasive ventilation. In subsequent weeks she was treated with three daily pulses of intravenous (IV) methylprednisolone I gram and IV immunoglobulin (2 grams/kilograms/day) for five days. She improved clinically with partial recovery of horizontal eye movements, improved swallowing and her anti-Ri antibodies became undetectable. Eight months after her first presentation she was, however, still artificially ventilated via a tracheostomy on the intensive care unit. At this point she suffered a further neurological relapse with recurrence of anti-Ri antibodies, worsening respiratory failure with recurrent chest sepsis, excess drooling, myoclonus, complete horizontal gaze paresis, asymmetric ptosis and proximal weakness. A repeat MRI scan of the brain showed abnormal high signal in the dorsal pons (Figures $2 \mathrm{~A}$ and B). She failed to respond to further IV methylprednisolone and immunoglobulin and no macroscopic tumour recurrence was detectable. She died six weeks after her relapse and an autopsy was performed.

A diagnostic neuropathology post-mortem was performed which revealed evidence of a highly localised and exclusively infratentorial encephalitic process involving the brainstem and cerebellum in particular. There was evidence of a prominent inflammatory infiltrate, composed of thymus $(T)$ and bursa-derived (B) cells, parenchymal clusters of CD8 positive cells and dense perivascular lymphocytic infiltrates containing polyclonal B cells and involving in particular the pons, medulla, cranial nerve nuclei and the circulatory and respiratory centres (Figure 3), these areas being in keeping with her clinical presentation. There was no macroscopic evidence of local or metastatic recurrence of breast carcinoma. 


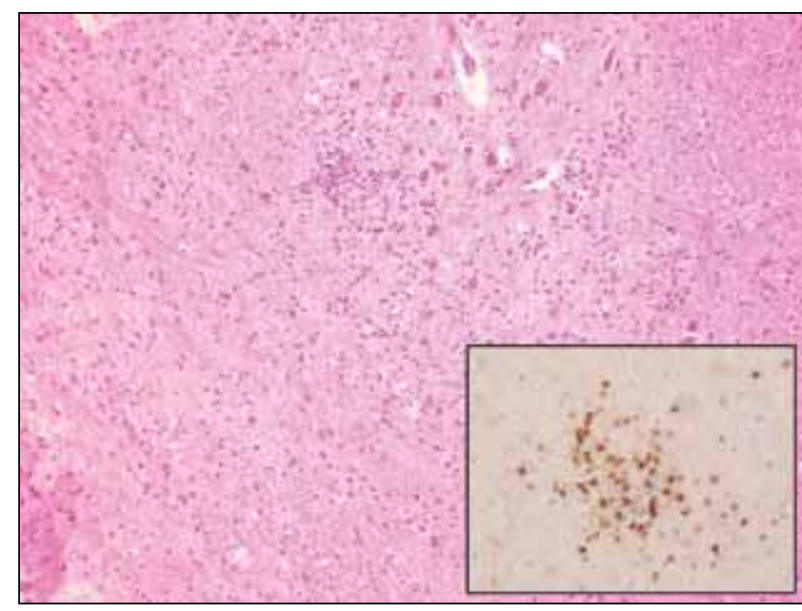

FIGURE 3 Haematoxylin and eosin stain of the lower pons showing scattered mononuclear infiltrates. The insert shows scattered parenchymal T cells (CD3) at the medullo-pontine junction and upper medulla.

\section{DISCUSSION}

The patient demonstrated an unusual brainstem neurological syndrome which is important to recognise because of its potential for progressive and irreversible deterioration. In conjunction with a normal MRI of the brainstem and modest CSF changes it is highly likely that such a brainstem syndrome is paraneoplastic. Urgent and extensive investigation to identify the underlying tumour is imperative since neurological outcome is dependent on the rapidity of commencement and efficacy of tumour therapy. Recovery can be limited once the neurological deficit is established. Furthermore clinicians must be aware of the potential for the brainstem syndrome to include impairment of the central respiratory drive that may lead to respiratory failure. The disparity between respiration when awake and asleep is crucial to identify. In our case the positive antineuronal screening provided rapid support for a paraneoplastic aetiology facilitating rapid planning of surgery.

Antineuronal antibodies can be found in both the serum and CSF of patients with paraneoplastic neurological syndromes and when detected in the context of an appropriate syndrome it is strongly suggestive of an underlying tumour (Table I).' Antineuronal antibodies are not always paraneoplastic and conversely their absence does not necessarily exclude a paraneoplastic syndrome. It is not the tumour type that correlates with the neurological phenotype but rather the associated antibody. SomeANNAs have been reported in association with multiple tumours whereas in others there is a more restricted subgroup of tumours (e.g. anti-Ri in breast and small cell lung cancer [SCLC] and anti-Ma in testis). The malignancy screen should also be informed by the relevant age and sex-related tumour incidence. Typically the neurological symptoms precede the diagnosis of the
TABLE I Antibodies, paraneoplastic syndromes and associated malignancy.

\begin{tabular}{|c|c|c|}
\hline Antibody & Syndrome & $\begin{array}{l}\text { Associated } \\
\text { malignancy }\end{array}$ \\
\hline $\begin{array}{l}\text { Anti-Hu } \\
\text { (ANNA-I) }\end{array}$ & $\begin{array}{l}\text { Encephalomyelitis, } \\
\text { brainstem degeneration, } \\
\text { sensory neuropathy, } \\
\text { autonomic dysfunction }\end{array}$ & $\begin{array}{l}\text { Small cell lung } \\
\text { cancer }\end{array}$ \\
\hline $\begin{array}{l}\text { Anti-Ri } \\
\text { (ANNA-2) }\end{array}$ & $\begin{array}{l}\text { Cerebellar degeneration, } \\
\text { brainstem encephalitis, } \\
\text { opsoclonus-myoclonus }\end{array}$ & $\begin{array}{l}\text { Breast, } \\
\text { gynaecological, } \\
\text { small cell lung } \\
\text { cancer }\end{array}$ \\
\hline $\begin{array}{l}\text { Anti-Yo } \\
\text { (PCA-I) }\end{array}$ & Cerebellar degeneration & $\begin{array}{l}\text { Breast, } \\
\text { gynaecological }\end{array}$ \\
\hline Anti-Ma & $\begin{array}{l}\text { Limbic, hypothalamic, } \\
\text { brainstem encephalitis }\end{array}$ & $\begin{array}{l}\text { Breast, germ- } \\
\text { cell tumours } \\
\text { of testis, lung } \\
\text { cancer }\end{array}$ \\
\hline Anti-NMDA & $\begin{array}{l}\text { Confusion, seizures, } \\
\text { dyskinesias }\end{array}$ & $\begin{array}{l}\text { Ovarian and } \\
\text { mediastinal } \\
\text { teratoma }\end{array}$ \\
\hline Anti-VGCC & $\begin{array}{l}\text { LEMS, cerebellar } \\
\text { dysfunction }\end{array}$ & $\begin{array}{l}\text { Small cell lung } \\
\text { cancer }\end{array}$ \\
\hline Anti-VGKC & $\begin{array}{l}\text { Neuromyotonia, limbic } \\
\text { encephalitis, seizures }\end{array}$ & Thymoma \\
\hline Anti-AchR & Myasthenia gravis & Thymoma \\
\hline \multicolumn{3}{|c|}{$\begin{array}{l}\text { PCA= purkinje cell antibody; } \mathbf{N M D A}=\mathrm{N} \text {-methyl-D- } \\
\text { aspartate VGCC= voltage-gated calcium channel; } \\
\text { VGKC= voltage-gated potassium channel; } \\
\text { AchR= acetylcholine receptor; } \text { LEMS= Lambert-Eaton } \\
\text { myasthenic syndrome }\end{array}$} \\
\hline
\end{tabular}

neoplasm and are often the initial reason that medical attention is sought.' Our patient tested positive for anti$\mathrm{Ri}$ antibodies and had evidence of a brainstem and cerebellar syndrome associated with breast malignancy. Other similar combinations have been described. ${ }^{2}$

Paraneoplastic neurological syndromes are usually associated with selective neurological disease e.g. hippocampal involvement in limbic encephalitis and antiYo antibodies with the cerebellum. ${ }^{4}$ Anti-Ri antibodies affect the brainstem and produce a clinically heterogeneous syndrome depending on the relative involvement of the various components affected. Findings may include opsoclonus-myoclonus, truncal ataxia, ophthalmoplegia and reduced central respiratory drive. The typical clinical course is of a subacute rapidly progressive neurological disorder worsening day by day. Neuropathology characteristically shows perivascular and parenchymal lymphocytic infiltrates in the brainstem. ${ }^{5}$ Magnetic resonance imaging in paraneoplastic neurological syndromes is characteristically initially normal but becomes abnormal after several weeks with neuronal atrophy. ${ }^{6}$ The abnormality seen is not pathognomonic but reflects the focal specificity of the 
process e.g. hippocampal high signal in limbic encephalitis. Management in all cases should be concentrated on detecting and treating the underlying malignancy. ${ }^{7}$ The role of immunosuppressive treatment is dictated by the cellular location of the antigenic molecule. ${ }^{8}$ If this is a surface molecule (voltage-gated potassium channel [VGKC], voltage-gated calcium channel [VGCC], acetylcholine receptor [AchR], N-methyl-D-aspartate [NMDA]) the antibody is likely to be pathogenic and so specific targeting of antibody function by plasma exchange or intravenous immunoglobulin (IVIg) will be beneficial.' Furthermore, as the mechanism of antibodymediated inhibition of function includes blocking and loss of channel activity rather than resulting primarily from neuronal loss, the potential for recovery in such circumstances is much higher. If the antigen is intracellularly located the immune related damage is considered to be mediated by cellular mechanisms and so is much less likely to be ameliorated by plasma exchange or IVIg and is rarely reversible. ${ }^{10}$ Prevention of further damage by removing the neoplastic stimulus for the immune response is the therapeutic goal. Thus immunosuppresive treatment should be restricted to steroids other than when a plasma membrane ANNA is identified. In this case IVIg was given on the basis of previous case reports of potential reversibility" but was not beneficial.

\section{CONCLUSION}

Our patient had a brainstem syndrome associated with breast cancer. She tested positive for an anti-Ri (ANNA2) autoantibody which is positively associated with this malignancy. Despite treatment of her cancer and immunological therapy her neurological impairment deteriorated and she died eight months after her first presentation.

\section{REFERENCES}

I Darnell RB, Posner JB. Paraneoplastic syndromes involving the nervous system. N Eng J Med 2003; 349:1543-54. http://dx.doi. org/I0.1056/NEJMra023009

2 Kim H, Lim Y, Kim KK. Anti-ri-antibody-associated paraneoplatic syndrome in a man with breast cancer showing a reversible pontine lesion on MRI. J Clin Neurol 2009; 5:15I-2. http://dx.doi. org/I0.3988/jen.2009.5.3.15I

3 Dalmau J, Rosenfield MR, Posner JB. Overview of paraneoplastic syndromes of the nervous system [Internet]. Massachusetts: Wolters Kluwer, Up to Date; 2011 [cited 2012 Jul 4]. Available from: http://www.uptodate.com/contents/overview-ofparaneoplastic-syndromes-of-the-nervous-system

4 Henson RA, Urich $\mathrm{H}$. Cancer and the nervous system. Oxford: Blackwell Scientific; I982. p. 3 I4.

5 Scaravilli F, An SF, Groves M et al. The neuropathology of paraneoplastic syndromes. Brain Pathol 1999; 9:25I-60. http:// dx.doi.org/I0.I I I I/j.I750-3639.1999.tb00224.x

6 Lawn ND, Westmoreland BF, Kiely MJ et al. Clinical, magnetic resonance imaging and electroencephalographic findings in paraneoplastic limbic encephalitis. Mayo Clinic Proc 2003; 78: 1363 8. http://dx.doi.org/10.4065/78.I I.1363

7 Rosenfeld MR, Dalmau J. Current therapies for paraneoplastic neurologic syndromes. Curr Treat Options Neurol 2003; 5:69-77. http://dx.doi.org/I0.1007/s I 1940-003-0023-y

8 Dalmau J, Gultekin HS, Posner JB. Paraneoplastic neurologic syndromes: pathogenesis and physiopathology. Brain Pathol 1999; 9:275-84. http://dx.doi.org/I0.IIII/j.1750-3639.1999.tb00226.x

9 Newsom-Davis J.Therapy in myasthenia gravis and Lambert-Eaton myasthenic syndrome. Semin Neurol 2003; 23:191-8. http://dx.doi. org/I0.1055/s-2003-4II35

10 Keime-Guibert F, Graus F, Fleury A et al. Treatment of paraneoplastic neurological syndromes with antineuronal antibodies (anti-Hu,anti-Yo) with a combination of immunoglobulins, cyclophosphamide and methylprednisolone. J Neurol Neurosurg Psychiatry 2000; 68:479-82. http://dx.doi.org/10.I I36/jnnp.68.4.479

I I Shams'ili S, Grefkens J, de Leeuw B et al. Paraneoplastic cerebellar degeneration associated with antineuronal antibodies: analysis of 50 patients. Brain 2003; 126:I409-18. http://dx.doi.org//0.1093/ brain/awg I 33 